\title{
Anorectal function in patients with complete supraconal spinal cord lesions
}

\author{
R MacDonagh, W M Sun, D G Thomas, R Smallwood, N W Read
}

\begin{abstract}
Anorectal manometry and sphincter electromyography were performed in 23 patients with complete supraconal traumatic spinal injuries and $\mathbf{3 0}$ age and sex matched control subjects. Basal pressures in the spinal group were similar to those in normal subjects but conscious control of sphincter activity was abolished in all spinal patients. Discriminant rectal sensation was also abolished during rectal distension, but $40 \%$ of patients experienced a dull pelvic ache at maximum levels of disténsion. Phasic rectal contraction and anal relaxation were present but exaggerated and induced at lower distending volumes than in normal subjects. The configuration of the rectal pressure/volume relationship was linear in patients compared with a reversed ' $S$ ' shape in normal subjects. The external anal sphincter response to rectal distension was noticeably attenuated, reinforcing the view that this spinal reflex is heavily modulated by supraspinal centres under normal circumstances. The external anal sphincter response to increases in abdominal pressure was also attenuated, and the anal pressures were strongly correlated with the level of the lesion and the abdominal pressure the patient could generate. No spinal patient showed a decrease in external anal sphincter activity during straining 'as if to defecate.' The exaggerated anorectal smooth muscle responses to rectal distension and the attenuated external sphincter response explain why patients with complete supraconal spinal lesions experience uncontrollable reflex defecation, while the persistance of external anal sphincter contraction and the absence of any external anal sphincter relaxation during straining 'as if to defecate' might explain the difficulty that these patients have in consciously expelling rectal contents. (Gut 1922; 33: 1532-1538)
\end{abstract}

Sinal Injuries Unit, Sheffield

R MacDonagh

D G Thomas

Gastrointestinal Motility Unit, Centre for Human Unit, Centrion, Northern General Hospital, Sheffield

W M Sun

N W Read

Department of Medical Physics and Clinical Engineering, Royal Hallamshire Hospital, Sheffield Sheffield

Correspondence to: Professor N W Read, Grofessor N W Read, Gastrointestinal Motility Unit, Centre for Human Nutrition,
Northern General Hospital, Northern General Sheffield S5 7AU. 11 May 1992

One of the most distressing aspects of spinal injury is an inability to regulate bowel function. Patients with complete supraconal lesions lose conscious control of defecation. Although they may be able to defecate reflexly by anorectal stimulation, evacuation is often inefficient and incomplete, resulting in a high incidence of constipation and faecal incontinence.'

A number of studies have investigated the disorders of defecation in spinally injured people, ${ }^{2-8}$ but most involve patients with incomplete lesions at different sites and caused by different mechanisms. ${ }^{4-7}$ In a previous study from our unit, ${ }^{7}$ we found that although patients with incomplete supraconal lesions retained the ability to contract their sphincters, damage to the long sensory and motor pathways was evident in the weak squeeze pressures and blunted rectal sensation. In addition the external anal sphincter response to rectal distension and increased intraabdominal pressure was often enhanced in patients compared with normal subjects, rectal compliance was abnormally low, anal relaxation and rectal phasic contractile responses to rectal distension were exaggerated, and there was no rebound increase in internal anal sphincter tone after rectal distension.

This study aimed to use the same methods to examine anorectal function in 23 patients with complete supraconal spinal cord lesions and to determinate the relationship between the site of the lesion and the existence of inconsistent phenomena. The results are compared with those from 30 age and sex matched controls.

\section{Patients and methods}

\section{PATIENTS}

Twenty three patients with complete traumatic supraconal spinal cord lesions were studied. The level of lesions was determined by detailed clinical neurological tests (both motor and sensory functions) (Table I). The group comprised 18 men and five women, aged 18-53 years (mean 30.3 ). The mean time since injury varied from $2-13$ years (mean $4 \cdot 4$ ). Twenty one patients stimulated bowel movements with either stimulant solutions (Dulcolax or Bisocodyl) or suppositories, though 15 of these had to complete rectal evacuation manually. Two patients used digital evacuation alone.

The control group consisted of 30 healthy subjects. There were 20 men and 10 women aged 16-60 years (mean 35). All passed stools of

TABLe I Patient details 
normal consistency at a frequency that varied from twice a day to three times a week. None had evidence of neurological disease or bowel disturbance.

Each subject gave written informed consent for the study to be carried out and the protocol was approved by the Ethical Committee of the Sheffield Area Health Authority.

\section{METHODS}

With the subject in the left lateral position and the hips flexed to $90^{\circ}$, a polyvinyl, seven lumen manometric probe with an external diameter of $4 \mathrm{~mm}$ was inserted into the rectum so that the manometric side holes were situated $0.5,1.0$, $2 \cdot 0,15$, and $18 \mathrm{~cm}$ from the anal verge. Each side hole was perfused with water at a rate of $0.2 \mathrm{ml} / \mathrm{minute}$ using a hydraulic capillary infusion system (Andorfer Medical Specialities Inc, Greendale, Wisconsin, USA). Pressures were measured using external strain gauge transducers (Druck Ltd, Groby, Leicestershire, UK) which were situated in each infusion line and connected via amplifiers to an eight channel chart recorder (Lectromed MT8 PX, Ormed Ltd, Welwyn Garden City, UK). A 6 cm length of distensible latex balloon was tied between 5 and $11 \mathrm{~cm}$ from the anal verge and used to inflate the rectum. The pressure in the rectal balloon was monitored using a non-perfused water filled catheter with a separate side hole within the balloon.

The electrical activities of the internal and external anal sphincters were recorded using bipolar electrodes, consisting of two trimel coated wires (diameter $=0.025 \mathrm{~mm}$ ) with their ends bared, hooked and offset to avoid electrical contact. In all of the patients and $50 \%$ of the control subjects, one pair of electrodes was inserted through the perianal skin into the superficial external anal sphincter and another pair was inserted through the anal epithelium into the internal anal sphincter. The remainder of the controls had a single pair of electrodes inserted into the intersphincteric groove, where they could detect the activities of both sphincters. The electrodes were attached to the chart recorder via an amplifier (Gould Electronic Ltd, Ilford, Essex, UK). The filter settings were 0.1 to $10 \mathrm{~Hz}$ for the internal and $10 \mathrm{~Hz}-10 \mathrm{KHz}$ for the external anal sphincter. The activity of the internal anal sphincter was displayed on the chart as regular oscillations while the external anal sphincter signal was integrated and displayed as an elevation above the baseline.

\section{PROTOCOL}

No bowel preparation was used. The spinal patients were instructed to empty their bowels in their usual manner the night before the test while the normal subjects were encouraged to defecate before the study if they felt the need to do so. Digital rectal examination was performed before insertion of the tube to ensure that the rectum was empty.

After insertion of the tube, anorectal motility was measured under resting conditions for 20 minutes. Subjects were then asked to carry out the following manoeuvres: (1) maximum voluntary contraction of the sphincter for 20 seconds; (2) strain as if to defecate for at least five seconds; and (3) increase intra-abdominal pressure by forcibly expiring against a resistance (blowing up a party balloon). Each manoeuvre was repeated after a gap of one minute. After a rest of five minutes the rectal balloon was serially inflated with $10,20,40,60$, and $100 \mathrm{ml}$ of air (intermittent inflation). Each inflation was maintained for one minute and separated by a gap of at least one minute from inflation with the subsequent volume. After a further rest period of 10 minutes the balloon was inflated with water at a constant rate of $50 \mathrm{ml} /$ minute using a peristaltic pump (Minipuls 3, Gilson 312, Villiers Le Bel, France) (ramp inflation).

\section{ANALYSIS OF RECORDS}

The resting record was analysed to determine the highest pressure recorded in the anal canal after insertion of the probe (maximum basal pressure) and then 20 minutes later, after it had achieved a stable baseline (minimum basal pressure). The presence or absence of increases in anal pressures and external sphincter electromyographic activity during a maximum squeeze, straining 'as if to defecate,' and forcibly expiring against a fixed resistance (blowing up a party balloon) were noted, and where relevant the responses quantified.

During intermittent rectal distension, the following indices were recorded:

(1) The number and amplitude of rectal contractions recorded $15 \mathrm{~cm}$ from the anal verge. (A rectal contraction was defined as a pressure increase of more than $5 \mathrm{cmH}_{2} \mathrm{O}$ sustained for at least three seconds).

(2) The lowest anal pressure achieved during anal relaxation (residual pressure) and the duration of relaxation.

(3) The occurrence and duration of external anal sphincter activity during rectal distension.

The following indices were recorded during ramp inflation: (1) the rectal pressure/volume relationship (pressures recorded during inflation of the balloon outside the body were subtracted from the values obtained in situ); (2) the frequency and amplitude of rectal contractions; (3) maximum distension volumes. In normal subjects inflation was ceased when pelvic discomfort was experienced. In the spinal patients, the maximum distension volume was taken to be either when the patients experienced autonomic symptoms or when the balloon was expelled automatically.

The statistical significance of the differences in pressure obtained was assessed using analysis of variance followed by Sheffe's method for multiple comparison. $\chi^{2}$ tests with Yates's correction were used to determine the differences between the proportion of subjects in each group.

\section{Results}

No differences were observed between male and female spinal patients for any of the variables tested in this study. 
Figure 1: Recordings of anorectal pressures from ports $0 \cdot 5,1 \cdot 0,2 \cdot 0,15$, and $18 \mathrm{~cm}$ from anal verge (channels 1, 2, 3, 5, and 6) and from a rectal balloon (channel 4) and electrical activity of sphincters during increases in intra-abdominal pressure induced by blowing up a party balloon in a typical normal control (left) and in a spinal patient (right). Note that while the rectal pressures increase in both groups, the increases in anal pressure and external anal sphincter electrical activity are significantly smaller in the spinal patient compared with the normal control.

Normal

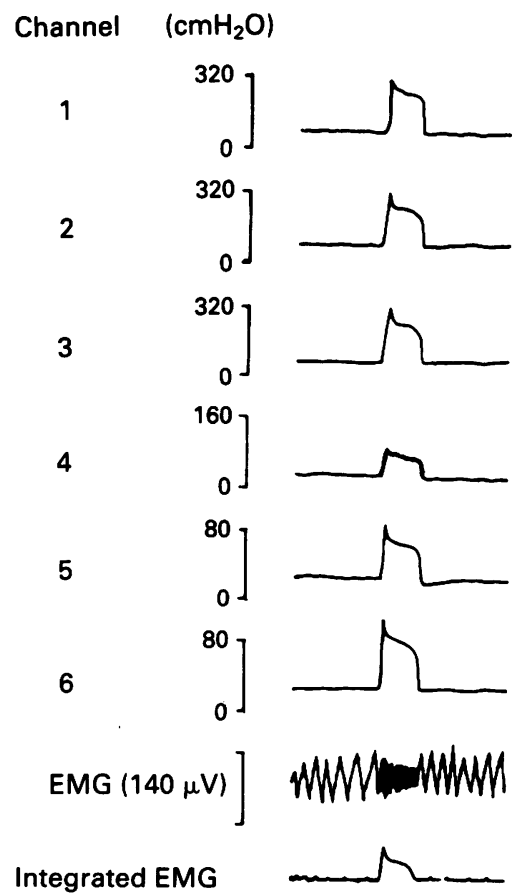

BASAL PRESSURE

In all control and spinal patients studied, there was an initial increase in external anal sphincter electromyographic activity on insertion of the anorectal tube which then declined in concert with the anal pressure to reach a stable baseline. The time taken to achieve a stable baseline was shorter in spinal patients compared with controls (median (range): $5(0-10)$ minutes $v 15(10-15)$ minutes; $\mathrm{p}<0.05)$. The minimum basal pressures in patients with complete supraconal spinal lesions were similar to those seen in control subjects (mean (SD) 50 (8) v 55 (6) $\mathrm{cmH}_{2} \mathrm{O}$ ), although the maximal basal pressures recorded immediately after tube insertion were lower (77 (9) $v 95$ (6) $\left.\mathrm{cmH}_{2} \mathrm{O}, \mathrm{p}<0.005\right)$.

\section{CONSCIOUS CONTROL OF THE EXTERNAL SPHINCTER}

All normal subjects could control their external sphincter at will, producing a rise in pressure (maximum squeeze pressure $=238(18) \mathrm{cmH}_{2} \mathrm{O}$ ) and an increase in electromyographic activity of the external sphincter. In contrast, none of the spinal patients produced an increase in anal pressure or an increase in external anal sphincter activity when asked to contract their sphincter.

\section{RESPONSE TO INCREASES IN INTRA-ABDOMINAL PRESSURE}

\section{Blowing up the balloon}

Increasing intra-abdominal pressure by asking subjects to blow up a balloon produced an increase in anal pressure in both controls and spinal patients, returning to the baseline after the action ceased. The rise in anal pressure during the manoeuvre was much lower in spinal patients

\section{Patient}

$\left(\mathrm{cmH}_{2} \mathrm{O}\right)$

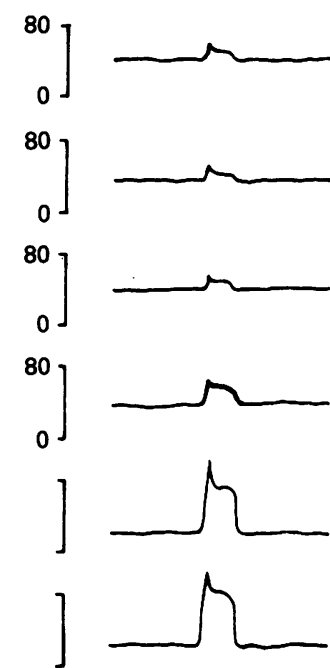

thmmmumth than in controls (Fig 1) and varied according to the level of the spinal lesion. Patients with cervical lesions produced the smallest rise (mean (SD) 3 (1) $\mathrm{cmH}_{2} \mathrm{O}$ ) compared with upper (T1-T5) and lower thoracic (T6-T12) injuries (22 (5) $\mathrm{cmH}_{2} \mathrm{O}$ and 54 (13) $\mathrm{cmH}_{2} \mathrm{O}$ respectively; $\mathrm{p}<0.01)$. These values were directly proportional to the increase in intra-abdominal pressure, indicated by the rise in rectal pressure (Fig 2).

\section{Straining}

Increasing intra-abdominal pressure by straining as if to defecate in control subjects produced a variety of anal pressure waveforms incorporating both anal contraction and anal relaxation (Table II), and corresponding with the external anal sphincter myoelectrical activity. The anal pressure profile in spinal patients always resembled that seen during rises in intra-abdominal pressure caused by inflating the balloon and did not show any anal relaxation or reduction in external anal sphincter activity.

The increases in anal and rectal pressure induced by straining were both significantly less in spinal patients than normal controls (anal pressures: spinal patients $44(6) \mathrm{cmH}_{2} \mathrm{O}$, controls $103(8) \mathrm{cmH}_{2} \mathrm{O}, \mathrm{p}<0.05$; rectal pressures: spinal patients $46(9) \mathrm{cmH}_{2} \mathrm{O}$, controls 62 (5) $\mathrm{cmH}_{2} \mathrm{O}, \mathrm{p}<0.05$ ).

\section{RESPONSES TO RAMP DISTENSION OF THE RECTUM}

\section{Rectal sensation}

Normal subjects experienced a range of sensations during inflation of a rectal balloon, starting with an initial perception at volumes of around $10 \mathrm{ml}$ and ranging through sensations of wind and desire to defecate to pain when the inflation was stopped. Fourteen patients with complete supraconal lesions did not report any sensation during rectal distension, the remaining nine reported a non-specific pelvic sensation that did not prevent further inflation of the rectal balloon. None of the four patients with cervical lesions experienced pelvic sensation.

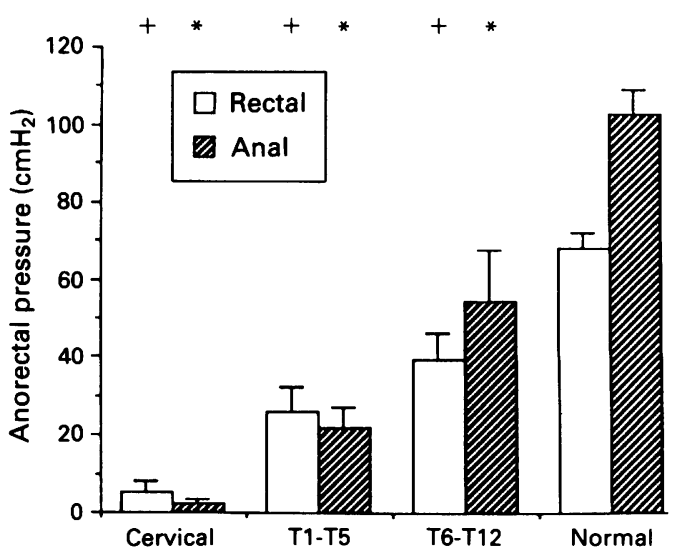

Figure 2: The increase in anorectal pressure upon blowing up a balloon in spinal patients with different levels of cord injury compared with normal subjects. ${ }^{*}$ Significant differences in anal pressures between patient group and normal subjects; + significant differences in rectal pressures between patient group and normal subjects. 
TABLE II The patterns of anal pressure profile observed during increases in intra-abdominal pressure and the proportion of each pattern in normal subjects and patients (\%)

\begin{tabular}{lll}
\hline & $\begin{array}{l}\text { Normal } \\
\text { subjects }\end{array}$ & $\begin{array}{l}\text { Patients } \\
(\%)\end{array}$ \\
\hline
\end{tabular}
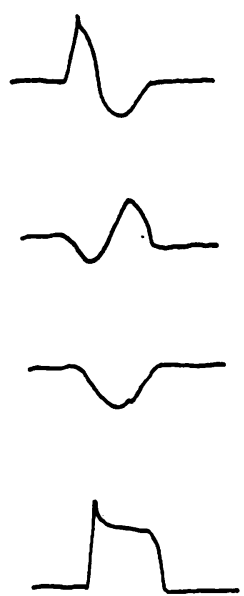

\section{Maximum tolerable volume}

As rectal volumes increased, all spinal patients with lesions above T6 $(n=11)$ experienced some degree of autonomic dysreflexia that prevented further rectal distension. This was manifest principally as flushing of the skin and sweating above the level of the lesion. The remaining 12 patients expelled the balloon automatically. The maximum tolerable volumes during ramp inflation were not significantly different in patients with complete supraconal lesions compared with normal subjects (normal subjects: mean (SD) 203 (14) ml; spinal patients: 238 (16) $\mathrm{ml}$ ), although clearly the criteria for the endpoint differed in each group.

\section{Rectal pressure/volume relationships}

The average pressure/volume relationship did not have the characteristic reversed ' $S$ ' shape characteristics seen in normal subjects and was linear in configuration (Fig 3). The initial slope was more shallow than in normal subjects (median: $0.19 v 0.57 \mathrm{cmH}_{2} \mathrm{O} / \mathrm{ml}$, Kruskal-Wallis test, $\mathrm{p}<0.05$ ) but later the slope became steeper (median: $0.12 v 0.04 \mathrm{cmH}_{2} \mathrm{O} / \mathrm{ml}, \mathrm{p}<0.05$ ).

\section{Rectal contraction}

Rectal contractions occurred in all normal and spinal patients on ramp inflation with increasing frequency, duration, and amplitude as distension of the rectum increased. Both the mean amplitude (spinal patients 31 (1) $\mathrm{cmH}_{2} \mathrm{O}$, controls $15(2) \mathrm{cmH}_{2} \mathrm{O}$ ) and duration (spinal patients 25 (6) seconds, controls 8 (1) seconds) of contractions in the spinal group were greater than in normal subjects $(p<0 \cdot 001)$, although the number of contractions seen throughout ramp inflation to $200 \mathrm{ml}$ were similar in both groups (total number, median, spinal $v$ normal $7 v 5 \cdot 5$; $\mathrm{p}>0.05$ ).
Large rectal contractions (pressure rise $>20$ $\mathrm{cmH}_{2} \mathrm{O}$ persisting for 10 seconds or longer) were seen significantly more frequently throughout ramp rectal distension in spinal patients (total number to $200 \mathrm{ml}$ distension, median; spinal patients $v$ normal subjects: $2 v 0.5, \mathrm{p}<0.01$ ).

Rectal contractions were associated with prolonged increases in external anal sphincter activity and anal pressure in all normal subjects. In 17 of the spinal injury patients $(74 \%)$ the external anal sphincter activity was either absent or much attenuated $(\mathrm{p}<0.0001$ compared with that in normal subjects).

\section{RESPONSES TO INTERMITTENT RECTAL DISTENSION}

\section{Rectoanal inhibitory reflex}

The rectoanal inhibitory reflex was present in all spinal and normal subjects. Internal anal sphincter relaxation increased in amplitude and duration in all spinal patients and normal controls as the rectum was distended intermittently with increasing volumes. The amplitude of the internal anal sphincter relaxation at low distension volumes was greater in spinal patients than in controls, and the residual pressures at each distending volume were significantly smaller $(p<0.05)$ (Fig 4). Similarly, the duration of anal relaxation was greater at low distension volumes in spinal patients compared with controls (Fig 5). On inflation with $100 \mathrm{ml}, 19$ of the 23 spinal patients $(83 \%)$ had maximal anal relaxation for the full 60 seconds of rectal distension compared with only 10 (33\%) of the control group $(p<0.02)$. There was no relationship between the level of the spinal lesion and the responses of the internal anal sphincter to rectal distension.

In normal subjects, the internal anal sphincter showed anal pressure increases upon deflating the rectal balloon that exceeded the predistending values (rebound response). The duration and amplitude of rebound pressure increased as the distension volume increased. This phenomenon was observed in only 4 of 23 spinal patients ( $<<0.001$ compared with normal) but the duration was shorter and the amplitude was

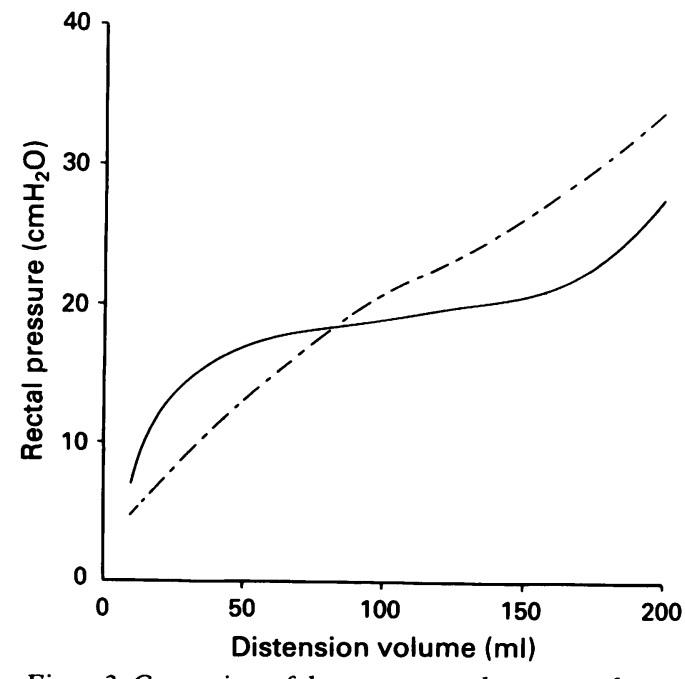

Figure 3: Comparison of the average rectal pressure volume relationships during ramp inflation of the rectal balloon in spinal injury patients $(--)$ and normal controls $(-)$. 


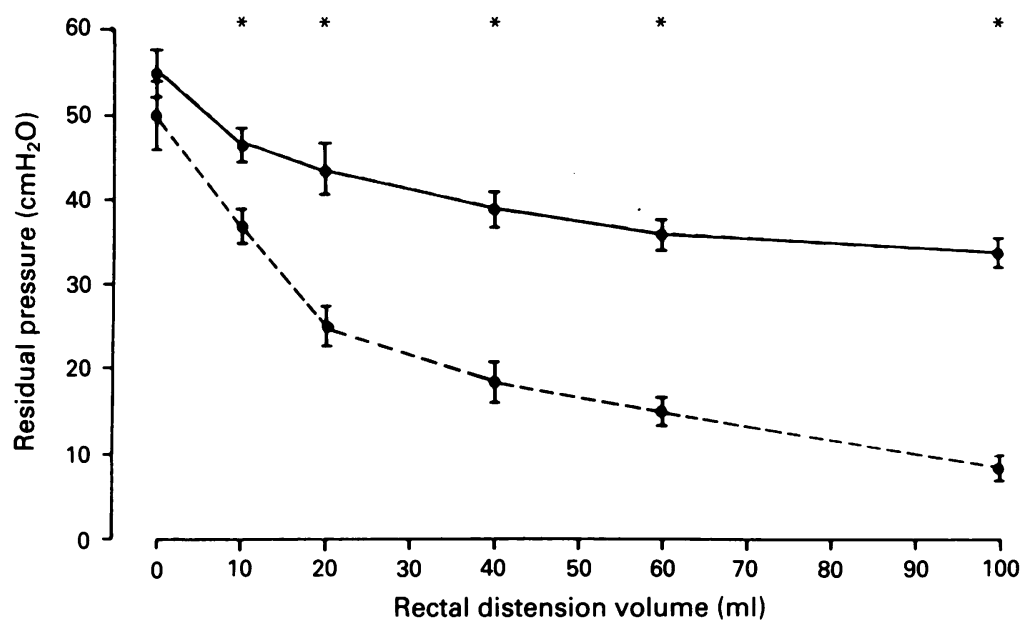

Figure 4: The residual anal pressure recorded during intermittent inflation of the rectum with air in spinal patients (- .--) and in normal controls $(-)$. ${ }^{\text {Significant differences between normal }}$ controls and spinal patients.

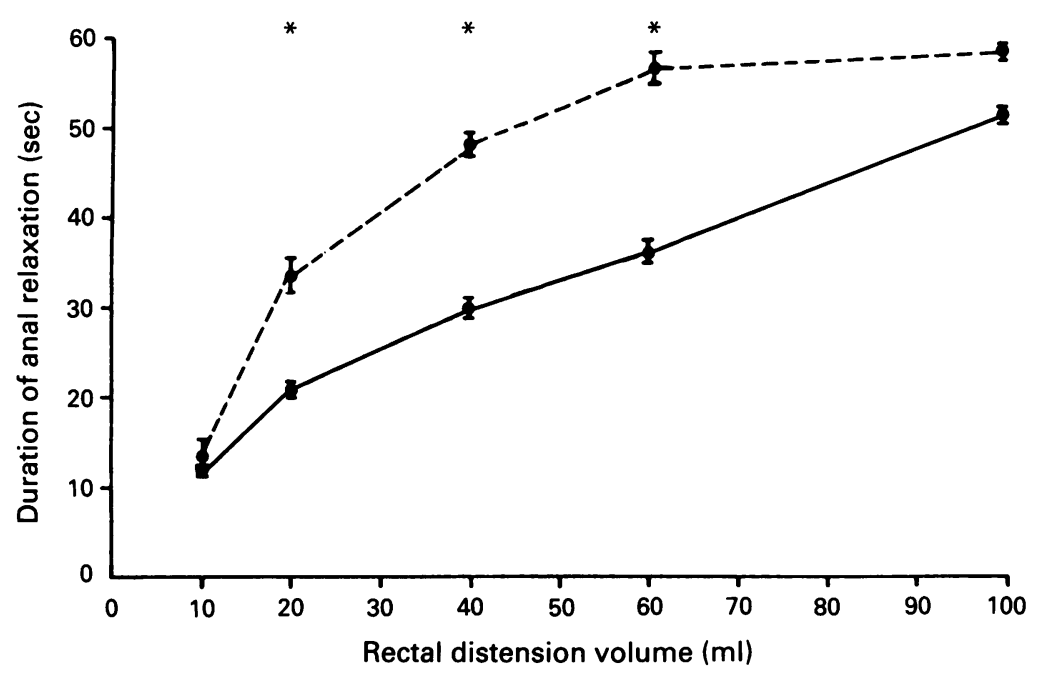

Figure 5: The duration of anal relaxation during intermittent inflation of the rectum with air in spinal patients (-) and normal controls (-). * Significant differences between normal controls and spinal patients.
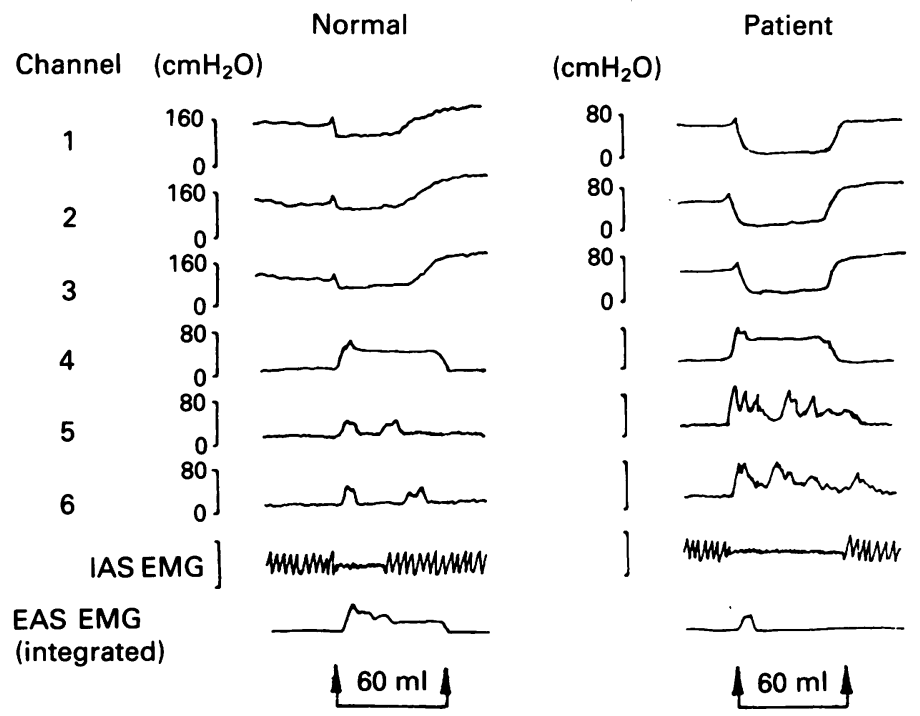

Figure 6: Anorectal pressure and myoelectrical activity of internal anal sphincter (IAS) and external anal sphincter $(E A S)$ in response to intermittent inflation of the rectum in a typical spinal patient (left) and a normal subject (right). Note that rectal distension with the same volume induces larger rectal contraction, less EAS activity and deeper IAS relaxations with no increases in IAS activity after deflating the balloon in the spinal patient compared with the normal subject. smaller (Fig 6). All four patients had cervical lesions.

\section{External anal sphincter responses}

The external anal sphincter responses to intermittent rectal distension were noticeably attenuated in spinal patients compared with normal subjects. In spinal patients, rectal distension caused an immediate increase in external anal sphincter activity, which never lasted longer than 10 seconds (Fig 6). In normal subjects, the duration of the external anal sphincter response was closely related to the duration of rectal contraction and the duration of rectal sensation and increased as the distending volume increased.

\section{Rectal contractions}

In normal subjects, rectal distension at lower volumes induced an initial pressure rise followed by a plateau, but at higher distending volumes $(>60 \mathrm{ml})$ two normal subjects showed repetitive rectal contractions that were compensated for by increased external anal sphincter activity (Fig 7). In all spinal patients the distension evoked uninhibited giant rectal contractions (pressure rise $>40 \mathrm{~cm} \mathrm{H}_{2} \mathrm{O}$ persisting for 10 seconds or longer) (Fig 8). The amplitude of these contractions became larger as the distending volumes increased (Fig 8). Giant contractions were always associated with enhanced internal anal sphincter relaxation and induced spontaneous balloon evacuation in nine patients (40\%) (Fig 7). Giant rectal contractions were never seen in normal subjects.

\section{Discussion}

The absence of both voluntary contraction of the external sphincter and rectal sensation confirms that patients with complete supraconal lesions lose conscious control of sphincter activity. These patients are unable to defecate voluntarily and must therefore rely upon stimulation of bowel reflexes with or without manual evacuation to complete defecation.

Increases in intra-abdominal pressure induced by inflating a balloon by mouth normally generate a compensatory increase in external anal sphincter activity that enhances the anal pressure barrier and maintains continence. This response is attenuated in patients with supraconal lesions, and is very strongly linked to the increase in intra-abdominal pressure; the higher the lesion, the lower the intra-abdominal pressure generated, and the lower the external anal sphincter response. Similar observations were made by Melzak and Porter $^{8}$ who showed that the external sphincter contractile response to a cough was greater, the lower the lesion. Patients with spinal lesions above T5 are unable to contract their abdominal muscles voluntarily but generate abdominal pressure by intercostal and diaphragmatic contraction. Those with cervical lesions, however, rely totally on diaphragmatic contraction. These observations reinforce the notion that the external anal sphincter response to increases in intra-abdominal pressure is a 
Spinal
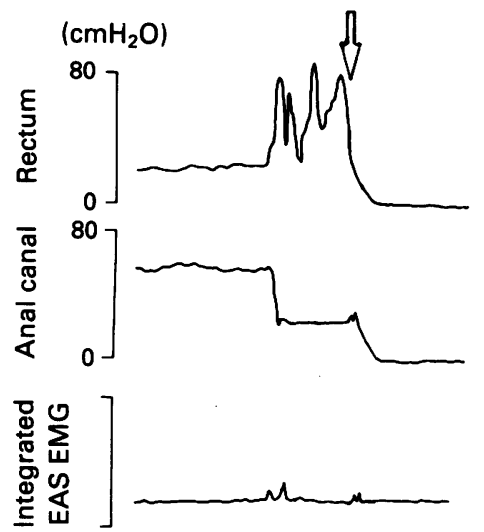

$60 \mathrm{ml}$
Control
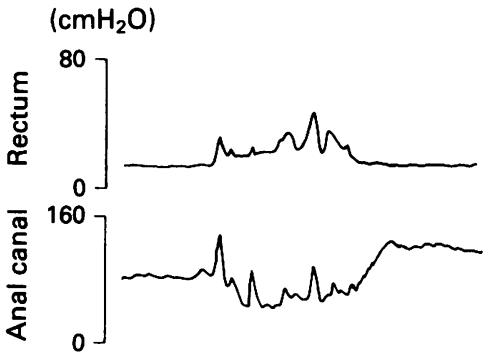

ఫ্ّ
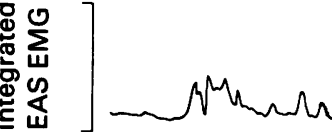

$60 \mathrm{ml}$

$1 \mathrm{~min}$

Figure 7: Anorectal pressure and external anal sphincter $(E A S)$ response to intermittent inflation of the rectum with $60 \mathrm{ml}$ of air in a patient with complete spinal lesion (spinal) and a normal control showing giant rectal contractions and an attenuated EAS response in the spinal patient. The arrows indicate that the balloon was expelled when rectal pressure exceeded residual anal pressure.

spinal reflex, triggered by tension receptors in the pelvis floor. ${ }^{9}$

Defecation requires the cortical inhibition of the external sphincter contraction in response to increases in intra-abdominal pressure. This may explain the biphasic external anal sphincter pressure response when some normal subjects strain 'as if to defecate.' None of our patients with supraconal lesions showed inhibition of the external anal sphincter when straining, confirming the importance of descending inhibitory pathways to facilitate defecation in normal subjects. This observation could explain why straining is often ineffective in promoting normal defecation even in low spinal patients with intact abdominal musculature.

Distension of the rectum facilitates defecation in patients with complete supraconal lesions by generating rectal contractions and anal relaxations in much the same way as in normal subjects. Both responses, however, were exaggerated in spinal patients, demonstrating giant contractions associated with deep anal relaxations and spontaneous expulsion of the balloon. These observations suggest that the rectal contractile response, which is thought to be a spinal reflex ${ }^{4}{ }^{10}$ and the internal sphincter relaxation, an enteric reflex, ${ }^{41}$ are both normally suppressed by descending inhibitory pathways.

It is likely that this inhibitory influence is conveyed via the sympathetic nervous connections. Stimulation of the sympathetic nerves is known to increase internal anal sphincter tone and inhibit colorectal contraction. ${ }^{12-14}$ The absence of a rebound internal anal sphincter response after deflation of the rectal balloon in all patients with a spinal transection at a level that would involve the sympathetic outflow would support interruption of sympathetic reflexes conveyed through the spinal cord. Inhibition of responses mediated via the sympathetic nervous system could also explain the absence of receptive relaxation of rectal tone during ramp distension of the rectum producing a linear pressure volume relationship. ${ }^{\text {is }}$ It is unlikely that all

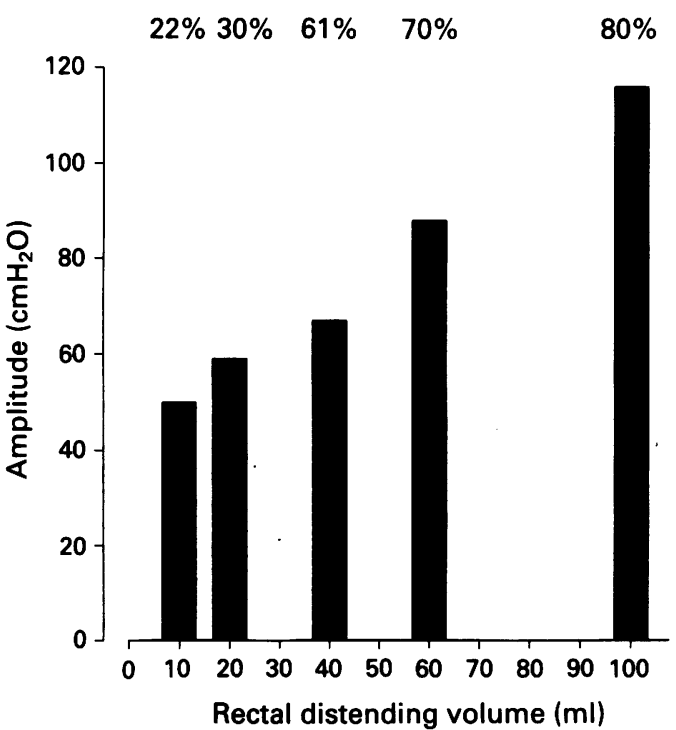

Figure 8: The amplitude of giant rectal contractions during rectal distension from 10 to $100 \mathrm{ml}$ in spinal patients and the percentages of patients who exhibited this phenomenon. Note that the amplitude of contractions became larger as the distending volumes increased and more patients exhibited such giant contractions.

sympathetic influence to the anorectum is abolished in spinal patients. Since the tone of the internal anal sphincter is normally modulated by its sympathetic nerve supply, ${ }^{12}$ the observation that the minimum basal pressure is no lower in spinal patients than in normal subjects suggests persistence of a tonic sympathetic influence on the internal anal sphincter, supporting previous studies, ${ }^{45}$ and probably mediated via autonomous activity of the inferior mesenteric ganglion. ${ }^{16}$

Although the spinal patients had no specific rectal sensation during rectal distension, almost half of them experienced a dull pelvic sensation at maximum distension. The origin of this is unclear, although it could derive from afferent impulses conveyed to the brain along sympathetic nerves that enter the thoracic spinal cord above the level of the lesion. The absence of pelvic sensation in the four patients with cervical lesions supports this interpretation.

The external anal sphincter response to rectal distension is very closely associated with both rectal sensation and rectal contraction in normal subjects, ${ }^{17}$ and presumably acts to prevent soiling. This response is either absent or very much attenuated in patients with supraconal lesions. This would explain the much lower residual pressures. It would also facilitate reflex defecation and predispose to faecal incontinence. These observations support previous conclusions that the external anal sphincter response to rectal distension is a spinal reflex, ${ }^{12}$ that has become extensively modulated by conscious mechanisms.

Comparison of the results of this study with those from our previous study shows that the major differences in anorectal function between patients with complete supraconal lesions and those with incomplete lesions are the almost complete loss of rectal sensitivity and the ability to contract the sphincter at will. Patients with complete lesions are also unable to generate such 
high abdominal pressures. Thus while patients with incomplete lesions retain some control of sphincter function, which can be enhanced by training, those with complete lesions have no control, are at the mercy of often unpredictable reflex defecation, and are best treated by transection of the dorsal sacral roots followed by manual evacuation or spinal stimulation, or both. ${ }^{18}$

This study was funded by the Medical Research Council, grant no G8723230N

1 Longo WE, Ballantyne GH, Modlin IM. The colon anorectum and spinal cord patient: a review of the functiona alterations of the denervated gut. Dis Colon Rectum 1989; 32 261-7.

2 Connell AM, Frankel H, Guttman L. The motility of the pelvic colon following complete lesions of the spinal cord. Paraplegia 1963; 1: 98-115.

3 Glick ME, Meshkinpour H, Haldeman S, Hoeler F, Downey $\mathrm{N}$, Bradley WE. Colonic dysfunction in patients with thoracic spinal cord injury. Gastroenterology 1984; 86: 287-94.

4 Denny-Brown D, Robertson ED. An investigation of the nervous control of defaecation. Brain 1935; 58: 256-310.

5 Frenkner B. Function of anal sphincters in spinal man. Gut 1975; 16: 638-44.

6 Aaronson MJ, Freed MM, Burakoff R. Colonic myoelectric activity in persons with spinal cord injury. Dig Dis Sci 1985; 30: $295-300$.
7 Sun WM, Read NW, Donnelly TC. Anorectal function in incontinent patients with cerebral spinal disease. Gastroincontinent patients with cerc

8 Melzak J, Porter NH. Studies of the reflex activity of the external sphincter ani in spinal man. Paraplegia 1964; 1 : 277-96.

9 Lane RHS, Parks AG. Function of the anal sphincter following colo-anal anastomosis. Brf Surg 1977; 64: 596-9.

10 White JC, Verlot MG, Ehrentheil O. Neurogenic disturbance of the colon and their investigation by the colonometrogram. Ann Surg 1940; 112: 1042-57.

11 Frenckner B, Ihre T. Influence of autonomic nerves on the internal anal sphincter in man. Gut 1976; 17: 306-12.

12 Gonella J, Bouvier M, Blanquet F. Extrinsic nervous contro of motility of small and large intestines and related sphincters. Physiol Rev 1987; 67: 902-61.

13 Garry RC. The responses to stimulation of the caudal end of the large bowel in the cat. $\mathcal{F}$ Physiol (Lond) 1933; 78: 208-24.

14 Gillespie JS. Electrical activity in the colon. In: Code CF, ed. Handbook of physiology. Alimentary canal motility. Vol IV. Washington, DC: American Physiological Society, 1968: 2093-120.

15 Glick ME, Meshkinpour H, Haldeman S, Hoehler F, Downey $\mathbf{N}$, Bradley WE. Colonic dysfunction in patients with thoracic spinal cord injury. Gastroenterology 1984; 86: 287-94.

16 Bouvier M, Grimaud JC. Neuronally mediated interactions between urinary bladder and internal anal sphincter motility in the cat. $\mathcal{F}$ P hysiol 1986; 346: 461-9.

17 Sun WM, Read NW. Anorectal function in normal subjects: effect of gender. Int $\mathcal{f}$ Colorect Dis 1989; 4: 188-96.

18 MacDonagh RP, Sun WM, Smallwood R, Forster D, Read NW. The control of defecation in patients with spinal injuries by stimulation of sacral anterior nerve roots. $B M \mathcal{F}$ 1990; 300: 1494-7. 